\title{
THE CONTRIBUTION OF A CAPSULE TO SURVIVAL OF STAPHYLOCOCCI WITHIN BOVINE NEUTROPHILS
}

\author{
J. C. Anderson AND M. R. Williams \\ AFRC Institute for Research on Animal Diseases, Compton, Newbury, Berks, \\ RG16 ONN
}

\begin{abstract}
SummaRY. The encapsulated strain M of Staphylococcus aureus and the encapsulated strain 76 of $S$. simulans survived incubation with bovine neutrophils in media containing heated bovine serum $0.5 \% \mathrm{v} / \mathrm{v}$ or milk whey $10 \% \mathrm{v} / \mathrm{v}$. With two unencapsulated strains of $S$. aureus, M12 and $\mathrm{M} 60,<5 \%$ of the original inoculum survived. When the concentrations of bovine serum and milk whey were increased to $2 \%$ and $50 \%$ respectively, survival of the encapsulated strains was similar to that of the unencapsulated strains. The ability of skimmed milk $50 \% \mathrm{v} / \mathrm{v}$ to opsonise strain $\mathrm{M}$ was found in milk from $95 \%$ of 62 cows.

The individual values for percentage intracellular survival of strains of $S$. aureus phagocytosed by bovine neutrophils in the presence of bovine serum $2 \% \mathrm{v} / \mathrm{v}$ or milk whey $50 \% \mathrm{v} / \mathrm{v}$ were $0.48,0.30$ and 0.24 for strains $\mathrm{M} 60, \mathrm{M}$ and $\mathrm{M} 12$ respectively. Intracellular survival of strain M60 was significantly greater than that of strains M12 and M. The encapsulated coagulase-negative strain 76 (S. simulans) was not susceptible to lysis by lysostaphin, and it was not possible to destroy extracellular staphylococci to measure intracellular survival. It is concluded that the capsule of $S$. aureus strain $\mathrm{M}$ does not contribute to intracellular survival.
\end{abstract}

\section{INTRODUCTION}

Most staphylococci within neutrophils are killed by the bactericidal reactions of the activated cells (Spitznagel, 1977). Verbrugh et al. (1978) reported that c. $88 \%$ of neutrophil-associated staphylococci are killed in vitro within $20 \mathrm{~min}$ with little difference in the killing capacity of neutrophils from 50 human donors. Although there was greater individual variation between cows, Williams et al. (1984) found that bovine neutrophils killed, on average, $90 \%$ of total staphylococci after incubation for $2 \mathrm{~h}$. However, a small proportion of staphylococci are not killed by phagocytes and it is these persistent organisms that trigger chronic inflammatory reactions. Persistent intracellular staphylococci are a feature of chronic staphylococcal mastitis in cattle (Anderson, 1982).

An antiphagocytic advantage conferred on staphylococci by the presence of a capsule has been demonstrated with $S$. aureus strain M (Melly et al., 1974), the Smith 
diffuse strain of $S$. aureus (Koenig, 1962) and S. simulans strain 76 (Anderson and Wilson, 1981). Peterson et al. (1978) have shown that the capsule of $S$. aureus strain M interferes with opsonisation by the classical and alternative complement pathways and by heat-stable factors in normal human serum. The capsule masks receptors for complement and immunoglobulin on the cell wall peptidoglycan (Wilkinson et al., 1979) and in this way inhibits ingestion. In the presence of specific anti-capsular antibodies, however, opsonisation and ingestion by human neutrophils occurs (Peterson et al., 1978). It is important to know if a capsule aids the survival of staphylococci once they are within neutrophils.

In this paper we report on the capacity of bovine serum and milk whey to opsonise encapsulated and unencapsulated staphylococci and on the survival of these organisms within bovine neutrophils.

\section{MATERIALS AND METHODS}

Neutrophils were obtained from fresh blood by the method of Carlson and Kaneko (1973). After centrifugation, $2.5 \mathrm{ml}$ of packed cells were mixed with $1.5 \mathrm{ml}$ of phosphate buffered saline (PBS) and the red cells lysed by the addition of $10 \mathrm{ml}$ of water. After $30 \mathrm{~s}$, isotonicity was restored by adding $5 \mathrm{ml}$ of saline $2.7 \% \mathrm{w} / \mathrm{v}$. The neutrophils were washed twice with $25 \mathrm{ml}$ of PBS and the concentration was adjusted to $10^{7}$ cells $/ \mathrm{ml}$.

Opsonins. Serum was pooled from 6,14 and 120 cows to provide three separate batches of serum. Pooled serum was heated for $30 \mathrm{~min}$ at $56^{\circ} \mathrm{C}$ and stored at $-20^{\circ} \mathrm{C}$. Three separate batches of milk whey were prepared from 3,9 and 20 cows respectively. The milk was centrifuged at $30000 \mathrm{~g}$ for $30 \mathrm{~min}$ and the unheated clear whey was frozen at $-20^{\circ} \mathrm{C}$. Serum and whey were sterilised by membrane filtration ( $0.45-\mu \mathrm{m}$ pore size; Millipore (UK) Ltd, Harrow, Middlesex) before use and dilutions were made in Hanks's Balanced Salts Solution.

Staphylococci. S. aureus strain M60 is a coagulase-positive staphylococcus that produces $\alpha$ and $\beta$ haemolysins on ox-blood agar. Strain M12 is a non-haemolytic strain of $S$. aureus. Strains M60 and M12 are unencapsulated and were originally isolated from cases of bovine mastitis. Strain M (NCTC 10649) is an encapsulated strain of S. aureus (Scott, 1969). Strain 76 is an encapsulated coagulase-negative staphylococcus classified as $S$. simulans (Anderson and Wilson, 1981).

Bacteria were grown overnight in $10 \mathrm{ml}$ of Todd-Hewitt Broth, washed twice with physiological saline and adjusted by nephelometry to a concentration of $c .6 \times 10^{6} \mathrm{cfu} / \mathrm{ml}$ of saline. Bacterial counts were determined by the technique of Miles et al. (1938). Strain $M$ was incubated on ox-blood agar at $30^{\circ} \mathrm{C}$ for $18 \mathrm{~h}$ because the mucoid colonies tended to coalesce at $37^{\circ} \mathrm{C}$. The other strains were incubated at $37^{\circ} \mathrm{C}$ for $18 \mathrm{~h}$. Extracellular staphylococci were eliminated by treatment with lysostaphin ( 240 units/mg: Sigma) at a final concentration of $5 \mu \mathrm{g} / \mathrm{ml}$ for $20 \mathrm{~min}$ at $37^{\circ} \mathrm{C}$. Lysostaphin was subsequently inactivated by trypsin (Difco) at a final concentration of $1.2 \mathrm{mg} / \mathrm{ml}$, before the mixtures were plated out on blood agar to enable colonies of $S$. aureus to grow from the intracellular survivors (Williams et al., 1985).

Experimental design and analysis. Preliminary tests were performed to establish the sensitivity of the bacterial strains to lysostaphin and opsonins without neutrophils. Suitable working concentrations of these variables with neutrophils were then established. Finally, the susceptibility of the opsonised bacterial strains to neutrophils was measured in five separate assays. The initial number of bacteria (T0) was recorded together with the total number of surviving bacteria (TS) and the number of intracellular survivors (ICS). Bacterial survival after incubation for $1.5 \mathrm{~h}$ with neutrophils and opsonins was expressed as a percentage of $\mathrm{T} 0$. The number of bacteria phagocytosed was calculated as T0 - (TS - ICS). Because phagocytosis is a necessary pre-requisite for bacterial destruction, the numbers of intracellular survivors were expressed as percentages of phagocytosed bacteria. The calculations are described in full by Williams et al. (1985). Analyses of the data were performed on the logarithms of these values; Student's $t$ test was used to analyse the $\log _{10} \%$ TS values of the preliminary experiments. Results of the main experiment were analysed by an analysis of variance mode that allowed for 
variations in source of neutrophils, assay and batch of opsonin before fitting bacterial strain, type of opsonin (serum or whey) and their interaction. When significant overall effects were detected, individual means were compared by Student's $t$ test.

\section{RESULTS}

\section{Strain differences in susceptibility to opsonisation and killing by bovine neutrophils}

In the standardised technique used in this laboratory for estimating the bactericidal activity of bovine neutrophils, S. aureus strain M60 was opsonised with heated pooled bovine serum $0.5 \% \mathrm{v} / \mathrm{v}$ final concentration (Williams and Bunch, 1981). The final concentrations of neutrophils and bacteria were $3 \cdot 3 \times 10^{6} / \mathrm{ml}$ and $1 \times 10^{6} / \mathrm{ml}$ respectively, and these were incubated for $1.5 \mathrm{~h}$ in the presence of opsonin. This concentration of serum or milk whey $10 \% \mathrm{v} / \mathrm{v}$ was opsonic for strains M60 and M12 (mean $\mathrm{TS}=4.8 \%$ ) but failed to opsonise strains $\mathrm{M}$ or 76 (mean TS $=100.9 \%$ ) (Table). When the opsonin concentrations were increased to serum $2 \% \mathrm{v} / \mathrm{v}$ and milk whey $50 \% \mathrm{v} / \mathrm{v}$, the mean number of survivors of either encapsulated or unencapsulated staphylococci was $<5 \%$ (4.9 and $3.8 \%$ respectively). These higher concentrations of opsonins failed to kill strains M60, M12 and M in the absence of neutrophils although the numbers of $S$. simulans strain 76 were reduced (table). The percentage TS for $S$. simulans in the absence of neutrophils was significantly lower than for the $S$. aureus strains after treatment with milk whey $10 \% \mathrm{v} / \mathrm{v}(\mathrm{p}<0.01)$, serum $2 \% \mathrm{v} / \mathrm{v}(\mathrm{p}<0.001)$ and milk whey $50 \% \mathrm{v} / \mathrm{v}(\mathrm{p}<0.001)$.

Although the average percentage survival rates for encapsulated and unencapsulated staphylococci were $<5 \%$ when the bacteria were incubated with neutrophils and serum $2 \% \mathrm{v} / \mathrm{v}$ or whey $50 \% \mathrm{v} / \mathrm{v}$, there were several effects of a particular opsonin on different strains and of different opsonins on a given strain. In serum $2 \% \mathrm{v} / \mathrm{v}$, strain $\mathrm{M}$ was less susceptible to phagocytic killing than strain M60 $(\mathrm{p}<0.01)$ but the results with strains $\mathrm{M} 12$ and 76 were not significantly different from those with strain $M(p>0.05)$. In milk whey $50 \% \mathrm{v} / \mathrm{v}$, the susceptibilities of strains M, M60 and M12 to phagocytic killing were not significantly different and all three strains were significantly more resistant than strain $76(\mathrm{p}<0.05)$. There were no differences between the three strains of $S$. aureus in response to type of opsonin, but phagocytic killing of strain 76 was significantly greater in whey $50 \% \mathrm{v} / \mathrm{v}$ than in serum $2 \% \mathrm{v} / \mathrm{v}(\mathrm{p}<0.01)$.

The milk whey pooled from three cows opsonised strain $\mathbf{M}$ poorly in two assays. In a subsequent assay, two of these three individual wheys failed to opsonise strain $\mathbf{M}(100$ and $140 \%$ TS respectively). This deficiency of opsonin for strain $\mathrm{M}$ in milk whey was investigated further by testing skimmed-milk samples, at a final concentration of $50 \%$ $\mathrm{v} / \mathrm{v}$, from 62 cows against strain $M$ with bovine neutrophils. Skimmed milk from three cows $(5 \%)$ failed to opsonise strain $\mathrm{M}(120 \% \mathrm{TS})$. In the remaining 59 samples, the geometric mean for the survival rates was $9 \%$. When the skimmed-milk samples were heated for $30 \mathrm{~min}$ at $56^{\circ} \mathrm{C}$, the number of samples that failed to opsonise strain $\mathrm{M}$ increased to six $(10 \%)$.

\section{Strain differences in susceptibility to intracellular killing by bovine neutrophils}

In preliminary tests, strains M60, M12 and M of $S$. aureus were killed after 


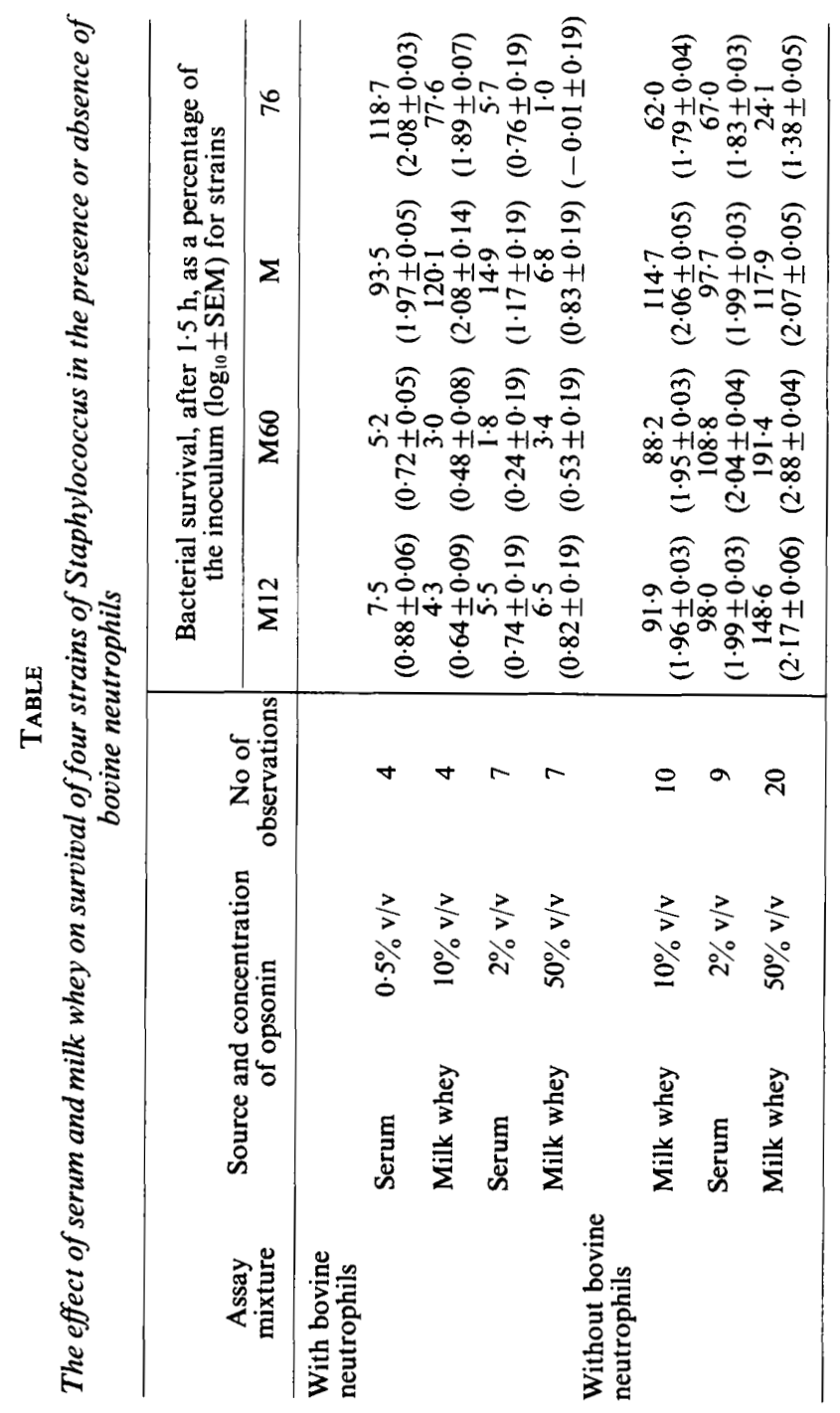


incubation for $20 \mathrm{~min}$ with lysostaphin $5 \mu \mathrm{g} / \mathrm{ml}(<0.01 \%$ TS). However, S. simulans strain 76 was not killed by lysostaphin concentrations up to $200 \mu \mathrm{g} / \mathrm{ml}$.

There were no differences between the effects of serum $2 \% \mathrm{v} / \mathrm{v}$ and milk whey $50 \%$ $\mathrm{v} / \mathrm{v}$ on intracellular killing of each of the three strains of $S$. aureus. The percentage intracellular survival $( \pm$ SEM) of phagocytosed bacteria was $0.24( \pm 0.045)$ for strain M12 (8 observations), 0.48 ( \pm 0.045$)$ for strain M60 (8 observations) and 0.30 $( \pm 0.048)$ for strain $M$ ( 7 observations). The difference between the intracellular survival of strains M12 and M was not significant, but survival of strain M60 within neutrophils was significantly greater than that of strains $M(p<0.01)$ or $M 12$ $(\mathrm{p}<0.001)$. Therefore, although phagocytosis and killing of strain M60 was greater than that of strain M, cells of strain M60 were more resistant to intracellular killing.

\section{Discussion}

Investigation of the role of a capsule in intracellular survival of staphylococci was made possible by the finding that bovine serum and whey opsonised the encapsulated strain M. With human serum, Peterson et al. (1978) found that ingestion of significant numbers of strain $M$ could not be achieved either by prolonging exposure to the opsonin or by increasing its concentration. In the present study, strain $\mathrm{M}$ was similarly resistant to phagocytosis in bovine serum $0.5 \% \mathrm{v} / \mathrm{v}$ or bovine whey $10 \% \mathrm{v} / \mathrm{v}$, but, when the concentrations were increased to $2 \% \mathrm{v} / \mathrm{v}$ and $50 \% \mathrm{v} / \mathrm{v}$ respectively, phagocytic ingestion was increased to the extent that, on average, $<5 \%$ of organisms of either encapsulated or non-encapsulated strains remained alive. Control preparations showed that, at these higher concentrations, the serum and whey were not themselves bactericidal but required the participation of neutrophils. The exception was with the coagulase-negative encapsulated $S$. simulans strain that grew significantly less well in the presence of serum or whey than the strains of $S$. aureus.

Because heated serum was opsonic for strain $M$, it appeared that antibody was predominantly involved. The absence of activity in two whey samples stimulated the examination of skimmed milk from 62 cows. Only $5 \%$ failed to opsonise strain $\mathrm{M}$ and this percentage increased slightly for heated skimmed milk, indicating the minor participation of complement. Both antibody and complement are normally involved in the opsonisation of unencapsulated staphylococci (Verbrugh et al., 1979) and specific anticapsular antibody is required for the opsonisation of encapsulated staphylococci (Verbrugh et al., 1982). Our results indicate that both antibody and complement are involved in opsonisation of strain $\mathbf{M}$ by bovine milk and that this activity is fairly widespread among cattle.

When the relative susceptibility of the three strains of $S$. aureus to killing by neutrophils was examined, strain $\mathbf{M}$ was significantly more resistant than one of the other $S$. aureus strains in heated serum $2 \% \mathrm{v} / \mathrm{v}$, but there was no difference between the strains in unheated milk whey $50 \% \mathrm{v} / \mathrm{v}$. The presence of small amounts of complement in whey $50 \% \mathrm{v} / \mathrm{v}$ (Mueller et al., 1983) may be sufficient to obliterate any difference in susceptibility to phagocytic killing between encapsulated and unencapsulated strains of $S$. aureus. Consistent with its behaviour in whey in the absence of neutrophils, the coagulase-negative strain 76 was significantly more susceptible to killing in whey in the presence of neutrophils than the $S$. aureus strains.

It was already known that the encapsulated strain $M$ was susceptible to lysis by 
lysostaphin (King et al., 1980) and the insensitivity of the encapsulated strain 76 to lysis by lysostaphin $(200 \mu \mathrm{g} / \mathrm{ml})$ was similar to findings with some unencapsulated coagulase-negative staphylococci and with micrococci (Schleifer and Kloos, 1975). Although it was not possible to measure the intracellular survival of strain 76 , an earlier study in mice showed that once neutrophils were recruited in response to intramammary inoculation of strain 76 , the organisms were rapidly eliminated from the glands (Anderson and Craven, 1984).

Intracellular survival of $S$. aureus was measured after lysis of extracellular staphylococci by lysostaphin (Easmon et al., 1978). Strain M60 had the greatest number of intracellular survivors. Survival was significantly greater than that of strains M12 and M; intracellular survival of strains M12 and M was not significantly different. The experiments indicated that a capsule does not increase intracellular survival of staphylococci.

The importance of this observation is two-fold. First, it helps to reveal the contribution of a capsule to virulence of staphylococci. The cardinal property of encapsulated strains of $S$. aureus is that they resist ingestion by phagocytes and they kill mice (Koenig, 1962; Melly et al., 1974). The identification of a coagulase-negative encapsulated staphylococcus that was resistant to phagocytic ingestion but was not lethal for mice indicated that encapsulation itself was not a lethal determinant (Anderson and Wilson, 1981). The present observation indicates that once encapsulated staphylococci are ingested their survival within neutrophils is not enhanced by the presence of a capsule. This further delimits the function of the capsule as a virulence determinant in staphylococci. Second, many strains of $S$. aureus isolated from cases of bovine mastitis are encapsulated (Opdebeeck and Norcross, 1983) and attempts have been made to immunise cattle against staphylococcal mastitis with capsular antigens (Yoshida et al., 1984). If encapsulated strains are common in clinical infections-and this has been challenged (Anderson, 1984) - the results suggest that anti-capsular antibodies may facilitate ingestion of staphylococci by neutrophils but would have no effect on intracellular persistence of staphylococci, which is the essential feature of staphylococcal mastitis (Anderson, 1982). Furthermore, although higher concentrations of serum and whey were required to opsonise encapsulated staphylococci, both serum and whey were able to support opsonisation at concentrations within physiological limits. Serum passes into milk as soon as inflammation begins in the mammary gland and there appears to be little need to provide additional opsonins in milk by immunisation with capsular antigens.

The authors thank T. R. Field for technical assistance, L. A. Williams for help with the analysis of variance and J. S. Howard for secretarial assistance.

\section{REFERENCES}

Anderson J C 1982 Progressive pathology of staphylococcal mastitis with a note on control, immunization and therapy. Veterinary Record 110:372-376.

Anderson J C 1984 Absence of encapsulation in strains of Staphylococcus aureus isolated from bovine mastitis. Research in Veterinary Science 37:359-361.

Anderson J C, Craven N 1984 Recruitment of neutrophils by an encapsulated coagulasenegative strain of Staphylococcus simulans in the mammary gland of the mouse. Journal of Leucocyte Biology 36:633-645. 
Anderson J C, Wilson C D 1981 Encapsulated, coagulase-negative strain of Staphylococcus simulans. Infection and Immunity 33:304-308.

Carlson G P, Kaneko J J 1973 Isolation of leukocytes from bovine peripheral blood. Proceedings of the Society for Experimental Biology and Medicine 142:853-856.

Easmon C S F, Lanyon H, Cole P J 1978 Use of lysostaphin to remove cell-adherent staphylococci during in vitro assays of phagocyte function. British Journal of Experimental Pathology 59:381-385.

King B F, Biel M L, Wilkinson B J 1980 Facile penetration of the Staphylococcus aureus capsule by lysostaphin. Infection and Immunity 29:892-896.

Koenig M G 1962 Factors relating to the virulence of staphylococci. 1. Comparative studies on two colonial variants. Yale Journal of Biology and Medicine 34:537-559.

Melly M A, Duke L J, Liau D F, Hash J H 1974 Biological properties of the encapsulated Staphylococcus aureus M. Infection and Immunity 10: 389-397.

Miles A A, Misra S S, Irwin J O 1938 The estimation of bactericidal power of the blood. Journal of Hygiene 38:732-749.

Mueller R, Carroll E J, Panico L 1983 Hemolytic complement titers and complement C3 levels in endotoxin-induced mastitis. American Journal of Veterinary Research 44:1442-1445.

Opdebeeck J P, Norcross N L 1983 Frequency and immunologic cross-reactivity of encapsulated Staphylococcus aureus in bovine milk in New York. American Journal of Veterinary Research 44:986-988.

Peterson P K, Wilkinson B J, Kim Y, Schmeling D, Quie P G 1978 Influence of encapsulation on staphylococcal opsonization and phagocytosis by human polymorphonuclear leukocytes. Infection and Immunity 19: 943-949.

Schleifer K H, Kloos W E 1975 A simple test system for the separation of staphylococci from micrococci. Journal of Clinical Microbiology 1: 337-338.

Scott A C 1969 A capsulate Staphylococcus aureus. Journal of Medical Microbiology 2:253-260.

Spitznagel J K 1977 Bactericidal mechanisms of the granulocyte. In: Greenwalt T J, Jamieson GA (eds) The granulocyte: function and clinical utilization. Alan R. Liss Inc, New York, pp 102-131.

Verbrugh H A, Peters R, Peterson P K, Verhoef J 1978 Phagocytosis and killing of staphylococci by human polymorphonuclear and mononuclear leucocytes. Journal of Clinical Pathology 31:539-545.

Verbrugh H A, van Dijk W C, Peters R, van der Tol M E, Peterson P K, Verhoef J 1979 Staphylococcus aureus opsonization mediated via the classical and alternate complement pathways. A kinetic study using Mg EGTA chelated serum and human sera deficient in IgG and complement factors C1s and C2. Immunology 36:391-397.

Verbrugh H A, Peterson P K, Nguyen B-Y T, Sisson S P, Kim Y 1982 Opsonization of encapsulated Staphylococcus aureus: the role of specific antibody and complement. Journal of Immunology 129:1681-1687.

Wilkinson B J, Peterson P K, Quie P G 1979 Cryptic peptidoglycan and the antiphagocytic effect of the Staphylococcus aureus capsule: model for the antiphagocytic effect of bacterial cell surface polymers. Infection and Immunity 23:502-508.

Williams M R, Bunch K J 1981 Variation among cows in the ability of their blood polymorphonuclear leucocytes to kill Escherichia coli and Staphylococcus aureus. Research in Veterinary Science 30:298-302.

Williams M R, Hibbitt K G, Field T R, Bunch K J 1984 Further studies on the variation among cows, bulls and calves in the ability of their blood polymorphonuclear leucocytes to kill Staphylococcus aureus. British Veterinary Journal 140:307-313.

Williams M R, Craven N, Field T R, Bunch K J 1985 The relationship between phagocytosis and intracellular killing of Staphylococcus aureus by bovine neutrophils. British Veterinary Journal 141:362-371.

Yoshida K, Ichiman Y, Narikawa S, Evans W B 1984 Staphylococcal capsular vaccine for preventing mastitis in two herds in Georgia. Journal of Dairy Science 67:620-627. 